\title{
Research on the Infringement Identification of the Specific Name for the Well- Known Commodity-Taking the Case of Lost in Thailand as an Example
}

\author{
Haiyan Qi \\ Sichuan Agricultural University, Ya'an, Sichuan, China \\ 1643076273@qq.com
}

Keywords: Well-Known Commodity, Right of Name, Infringement Act

\begin{abstract}
In the case of Lost on Journey and Lost in Thailand, the audience suddenly realize that they are not series. Meanwhile, the case also let people know that the specific names for well-known commodities have great commercial value and it is also an important right protected by law. Strengthening the protection of the right of specific names for well-known commodities is an important part of protecting intellectual property rights and flourishing the cultural market.
\end{abstract}

\section{Introduction}

In 2013, the plaintiff of Wuhan Huaqi film and television production company, as the copyright owner of Lost on Journey, brought a lawsuit to the Beijing High People's Court. The Enlight Media Company and other three producers of Lost in Thailand had "unfair competition and copyright infringement". In September 2014, the court made a first instance judgment and ruled that The Enlight Media Company and other producers had unfair competition.The Enlight Media Company, $\mathrm{Xu}$ Zheng the director and other producers must jointly compensate five millions yuan to Wuhan Huaqi for economic loss. The defendant refused and appealed.Five years later on April 9, 2018, the Supreme People's Court had made a final decision that the movie Lost in Thailand violated the specific name of the movie Lost on Journey, and the defendant linked Lost in Thailand and Lost on Journey in public statements can easily confuse consumers. In the end, the court, on the grounds of the fact that Lost in Thailand violated the relevant provisions of the Anti Unfair Competition Law and the Tort Liability Law of the People's Republic of China and infringed the rights of the plaintiff, sentenced that $\mathrm{Xu}$ Zheng the director of Lost in Thailand and the five other producers including The Enlight Media Company and The true Music Company made an indemnity of five millions to Wuhan HuaQi Film and Television Company, the copyright owner of Lost on Journey. In view of the high popularity and influence of both films in this case, the result of the judgement is very sensitive. In the case, the court identified the film as a well-known commodity, so it should be protected by law because of its great commercial value according to the Anti Unfair Competition Law which has made a clear provision for the specific name right for well-known commodity.

\section{The specific name right for well-known commodity}

Article 6 of the Anti-Unfair Competition Law (the following short for anti-law) stipulates that the operator shall not implement the following confusing behaviors, which may be mistaken for other people's goods or has a specific connection with another person:

(1) unauthorized use of the same or similar marks as the names, packages and decorations of goods that have certain effects on others;

(2) unauthorized use of the names of enterprises (including abbreviations, names, etc.) and social organization names (including abbreviations, etc.) and names (including names, stage names, translations, etc.);

(3) unauthorized use of the main body part of the domain name, website name, webpage, etc.;

(4) other obfuscating behaviors that can be mistaken for other people's goods or have specific links with others[1]. 
The commodity name is one of the important representations of commodities. The anti-law prohibits the unauthorized use of the specific name for well-known commodity or the use of its approximate name. The name here refers to the name of a commodity that is unique to a well-known commodity and it is fairly distinguished from the generic name. According to the interpretation of the Supreme People's Court on the application of laws on the trial of civil cases of unfair competition, the well-known commodity refers to the goods that have a certain market popularity in China and are known to the relevant public. It is concluded that identifying the well-known commodity should be taken into account the sales of time, area, volumes, and marketing object, the duration of any publicity, degree, geographical scope, protection conditions and other factors and then makes a comprehensive judgement[2]. The proprietor's unauthorized use of the specific name for well-known commodity or the use of a name similar to the name of another person's commodity are easy to cause the misunderstanding of consumers, which belongs to the unfair competition.But in this case, the biggest controversy between the two sides is whether the film is a well-known commodity with its $\$ 50$ million box office.Movie box office is determined by many factors, and it can not fully represent the popularity of the product. Because of its issue, Lost on Journey has a short time for publication and inadequate publicity, so the box office is relatively low. On the major video web sites, the amount of play is huge and the score in douban is 7.5. It is its high reputation that has triggered a large number of clicks, so it is no doubt that it is recognized as a well-known commodity. The four Chinese characters of Lost on Journey, the Chinese name of the film, already have a very large popularity, and its popularity is representative of commercial value, so it should be protected by law.

\section{Behavior and identification of infringement of the right of specific names for well-known commodities}

There are two ways of infringing the specific name for well-known commodity: the first is to use its commodity name without authorization; the second is to use its similar name.In this case, the defendant uses a similar name. Lost in Thailand means once again on the Jiong road, with a sequel or second impression, and many viewers think that it is the original sequel. The defendants had repeatedly said in open interviews that their work was an upgraded version and a sequel to Lost on Journey, and referred to the "original cast." These misleading and false propaganda are all about stealing the commercial value and popularity of Lost on Journey. It can be said that a lot of audience are based on the approval of the original, and a large portion of the $\$ 1.267$ billion in the box office acquired by Lost in Thailand is the contribution of the original work. For the determination of such infringement, first of all, it is necessary to determine whether the specific name for well-known commodity is the same or similar, and whether it is enough to cause consumers to misunderstand. There is only one word difference between Lost on Journey and Lost in Thailand. They both have sequentially accepted relationship and their names are enough to cause misrecognition, so that consumers consider it sequel or second. Second, it should be made sure that the user has been exposed to the user's product, or has access to it. This requires identifying "well-known commodities." Famous commodities have certain popularity and influence in China's domestic market. As long as it is recognized as a well-known commodity, then in the same industry, the user can be presumed to know the product. In the case, Xu Zheng is the leading actor in the two film. He has appeared in the plaintiff's works, and the original work is a well-known commodity, so Xu Zheng should have known the work naturally. Finally, it is necessary to make sure that the use of the specific name for the wellknown commodities of others causes losses to others. On the basis of the good reputation and market prospect of the film, the producer is ready to invest in the sequel and has made a lot of preparations.But the result is a pre-emptive release of Lost in Thailand, which seriously damages its commercial interests. With the box office earnings and good word of mouth, it can be seen that if the studio shoots the second movie, it won't go down anywhere, even if it's not as high as Lost on Journey. But the profit opportunity was ruthlessly wiped out by the infringers. As long as the three requirements are met, it should be considered as infringement. 


\section{Strengthening the protection of specific names for well-known commodities}

The commercial value of the specific name for well-known commodity is beyond doubt, and it is necessary to protect it. Although the anti-law has already stipulated such problems, it is too simple to solve practical problems. To protect the right of specific names for well-known commodities, it should be proceeded from the following aspects:

First, to set up a specific well-known commodity recognition institution. The recognition mechanism of the well-known trademarks in China is fairly perfect.The cognizance of well-known commodities can be set up according to the procedure and system of well-known trademark recognition, and the visibility requirement of well-known commodities should be lower than that of well-known trademarks. There are two ways to identify well-known trademarks in China, namely, judicial and administrative cognizance. So the cognizance of well-known commodities can also have these two kinds of means.It can apply to the administrative competent authority for recognition as a well-known commodity, or in judicial practice, request the court to identify it as a well-known commodity.

Second, to establish standards for the recognition of well-known commodities. According to the interpretation of the Supreme People's Court on Several Issues concerning the application of law in civil cases involving unfair competition, a well-known commodity is a commodity that has certain market awareness in China and is known to the relevant public. The criteria for identifying wellknown commodities shall include the following factors: the sales of time, area, volumes, and marketing object, the duration of any publicity, degree, geographical scope, protection conditions and other factors. Determining a complete set of reference standards so that it can provide specific guidelines for the identification of well-known goods and facilitate the identification of the right holder.The protection of intellectual property requires everyone's respect for intellectual property rights. Citizens should raise their legal awareness to understand and master relevant laws and regulations on intellectual property rights, to protect their intellectual property rights, and to respect other people's intellectual property rights. Only when intellectual property rights are protected, can we fundamentally make knowledge progress, promote cultural prosperity and contribute to social development.

\section{Conclusion}

The specific name rights for well-known commodities have great commercial value and they are intellectual achievements of the obligee, whose intellectual property rights should be protected by law and respected by others. The unauthorized use of the specific name for the well-known commodities leads to the misunderstanding of the consumers and damaging the interests of others, so infringer shall be punished by the law and bear the legal responsibility. The right holder and each citizen should also attach importance to protect the specific name rights for well-known commodities.

\section{References}

[1]The law on anti unfair competition in the People's Republic of China.

[2]Chun tian Liu, intellectual property law, Renmin University of China press, pp.353, 2015. 